\title{
An observational feasibility study - does early limb ergometry affect oxygen delivery and uptake in intubated critically ill patients - a comparison of two assessment methods
}

Olive M Wilkinson ${ }^{1 *}$, Andrew Bates ${ }^{2}$ and Rebecca Cusack ${ }^{1,2^{*}}$

\begin{abstract}
Background: Early rehabilitation can reduce ventilation duration and improve functional outcomes in critically ill patients. Upper limb strength is associated with ventilator weaning. Passive muscle loading may preserve muscle fibre function, help recover peripheral muscle strength and improve longer term, post-hospital discharge function capacity. The physiological effects of initiating rehabilitation soon after physiological stabilisation of these patients can be concerning for clinicians. This study investigated the feasibility of measuring metabolic demand and the safety and feasibility of early upper limb passive ergometry. An additional comparison of results, achieved from simultaneous application of the methods, is reported.
\end{abstract}

Methods: This was an observational feasibility study undertaken in an acute teaching hospital's General Intensive Care Unit in the United Kingdom. Twelve haemodynamically stable, mechanically ventilated patients underwent 30 minutes of arm ergometry. Cardiovascular and respiratory parameters were monitored. A Friedman test identified changes in physiological parameters. A metabolic cart was attached to the ventilator to measure oxygen uptake. Oxygen uptake was concurrently calculated by the reverse Fick method, utilising cardiac output from the LiDCO ${ }^{\text {TM }}$ and paired mixed venous and arterial samples. A comparison of the two methods was made. Data collection began 10 minutes before ergometry and continued to recovery. Paired mixed venous and arterial samples were taken every 10 minutes.

Results: Twelve patients were studied; 9 male, median age 55 years, range (27-82), median APACHE score 18.5, range (7-31), median fraction inspired oxygen $42.5 \%$, range (28-60). Eight patients were receiving noradrenaline. Mean dose was $0.07 \mathrm{mcg} / \mathrm{kg} / \mathrm{min}$, range (0.01-0.15). Early ergometry was well tolerated. There were no clinically significant changes in respiratory, haemodynamic or metabolic variables pre ergometry to end recovery. There was no significant difference between the two methods of calculating $\mathrm{VO}_{2}(p=0.70)$.

(Continued on next page)

\footnotetext{
*Correspondence: Olive.Wilkinson@gmail.com; Rebecca.Cusack@uhs.nhs.uk

'Centre for Innovation and Leadership, Faculty of Health Sciences, University

of Southampton, Building 45, Room 2035, Highfield Campus, S017 1BJ

Southampton, UK

Full list of author information is available at the end of the article
}

(c) The Author(s). 2021 Open Access This article is licensed under a Creative Commons Attribution 4.0 International License, which permits use, sharing, adaptation, distribution and reproduction in any medium or format, as long as you give appropriate credit to the original author(s) and the source, provide a link to the Creative Commons licence, and indicate if changes were made. The images or other third party material in this article are included in the article's Creative Commons licence, unless indicated otherwise in a credit line to the material. If material is not included in the article's Creative Commons licence and your intended use is not permitted by statutory regulation or exceeds the permitted use, you will need to obtain permission directly from the copyright holder. To view a copy of this licence, visit http://creativecommons.org/licenses/by/4.0/ The Creative Commons Public Domain Dedication waiver (http://creativecommons.org/publicdomain/zero/1.0/) applies to the data made available in this article, unless otherwise stated in a credit line to the data. 
(Continued from previous page)

Conclusions: We report the feasibility of using the reverse Fick method and indirect calorimetry to measure metabolic demand during early physical rehabilitation of critically ill patients. More research is needed to ascertain the most reliable method. Minimal change in metabolic demand supports the safety and feasibility of upper limb ergometry. These results will inform future study designs for further research into exercise response in critically ill patients.

Trial Registration: Clinicaltrials.gov No. NCT04383171. Registered on 06 May 2020 - Retrospectively registered. http://www.clinicaltrials.gov.

Keywords: Early rehabilitation, Physiological response, Critical care

\section{Background}

In 2017-2018 there were over 290,000 adult Intensive Care Unit (ICU) patient records in England, of whom $7.4 \%$ had a length of stay duration of eleven days and more [1] In the critically ill patient muscle wasting can occur within hours of the initiation of mechanical ventilation and may be exacerbated by multi-organ failure, heavy sedation and immobility [2-4]. The consequences for survivors include long-term physical disability, poor quality of life and increased associated health care costs $[5,6]$.

A number of studies have reported that the early application of ICU mobility therapy can reduce the number of ventilator days, ICU and hospital length of stay [7, 8] as well as improving functional outcome at hospital discharge $[9,10]$. Although, early ICU mobility therapy studies have reported minimal safety issues, there are concerns that such activities, undertaken during the acute phase of critical illness may result in additional, unreported metabolic demands.

Oxygen consumption is a widely used proxy measure for metabolic rate. Within the ICU, whole body oxygen consumption can be determined by using paired arterial and venous blood oxygen content, in conjunction with cardiac output monitoring. (The reverse Fick method). Alternatively, indirect calorimetry techniques provide a minimally invasive assessment of energy consumption, using a metabolic cart, attached to the ventilator measures breath by breath, inhaled and exhaled oxygen and carbon dioxide. [11]. However, the precision and reliability of indirect calorimetry in the critically ill patient has been questioned [12].

The primary objective of our study was to assess the feasibility of using the reverse Fick method and indirect calorimetry to measure metabolic demand and to assess the safety and feasibility of passive upper limb cycle ergometry, during the first days of critical illness. A secondary objective analysis will compare simultaneous assessment of the two methods of assessing oxygen uptake $\left(\mathrm{VO}_{2}\right)$. We hypothesize that measuring oxygen consumption during passive exercise in critically ill patients is feasible and will demonstrate minimal metabolic demands on the patient. This study is reported in accordance with the STROBE statement [13].

\section{Methods}

This observational feasibility study was conducted in a 25-bed University Teaching Hospital ICU in the United Kingdom. Ethical approval was granted by South Central - Hampshire National Research and Ethics Service. Reference: 14/SC/1398.

\section{Patient recruitment}

All patients admitted to the ICU with a medical diagnosis and requiring intubation and ventilation for at least 48 hours join an Early Mobility Program (EMP). This programme provides a progressive mobility pathway starting with daily passive upper/lower limb exercise sessions by means of an ergometer in addition to their routine physiotherapy. Inclusion criteria for enrolment into the study included: patient being on the EMP pathway of which the criteria were cardiovascular stability (stable vasopressor dose for two hours); stable heart rate (< $140 \mathrm{bpm}$ ) and rhythm and the presence of a jugular central venous pressure (CVP) line and arterial line. Exclusion criteria included any prior rapidly deteriorating neuromuscular disease, any upper limb problem precluding cycle ergometry, pyrexia (temp $>38{ }^{\circ} \mathrm{C}$ ), raised intracranial pressure, patients with poor prognostic outcomes and lack of agreement from clinician or NOK/LR not understanding English. 149 patients accepted onto the EMP were screened for study eligibility.

All included patients had monitoring in place that included: electrocardiogram (ECG) set, saturation probe, CVP line and an arterial line. Patients were sedated according to the ICU sedation protocol using a combination of fentanyl, midazolam and/or propofol aiming for a RASS score between -1 and +1 . Vasopressors were used to maintain a mean arterial blood pressure of $>75$ $\mathrm{mmHg}$. Sedative infusion rates and ventilation settings were not changed during the protocol.

Patients were ventilated using pressure or volume control modes or support mode using an Engstrom Caresta$\operatorname{tion}^{\mathrm{TM}}$ ventilator. Flow volumes were directly measured 
by a ventilator D-lite ${ }^{\text {tw }}$ sensor, which measures pressure difference between two ports and calculates gas/air flow (GE Healthcare, Chicago, Illinois).

\section{Early mobility interventions}

Patients were positioned in bed, in a semi recumbent position with their arms in the limb supports of the cycle ergometer (MOTOmed letto2 - Reck, Reckstr $1-5$, Betzenweiler 88,422, Germany). Sixty minutes of data was collected. The first 10 minutes were with patients upper limbs positioned in the limb supports and at rest followed by 30 minutes passive upper limb cycling at a frequency of 20 revolutions per minute, and finally 20 minutes with the patients upper limbs left in the limb supports during which the patient was at rest undisturbed. Safety criteria used for patient initiation and continued use of the ergometer was based on the traffic light system recommended from Hodgson et al. [14] .

\section{Measurements}

Continuous heart rate (HR), blood pressure (BP), heart rhythm and saturations were measured throughout the 60-minute study period for each patient. Continuous cardiac output (CO) L/min, HR (bpm), BP $(\mathrm{mmHg})$, and stroke volume $(\mathrm{SV}) \mathrm{m} / \mathrm{L}$ were monitored by the $\mathrm{LiDCO}^{\mathrm{mw}}$. The $\mathrm{LiDCO}^{\mathrm{tw}}$ was calibrated as per manufacturer guidance, prior to patient enrolment. Minute by minute values of inspiratory and expiratory $\mathrm{O}_{2}$ and $\mathrm{CO}_{2}$, respiratory rate (RR) breaths/ min, minute volume $(\mathrm{MV}) \mathrm{mL}$ and tidal volume $\left(\mathrm{V}_{\mathrm{T}}\right)$ $\mathrm{mL}$ were measured by the ventilator's E-COVX module. Values for all continuous data were averaged over the five minutes leading up to each 10-minute interval within the 60-minute study period. If any data was missing within those last five minutes the average was calculated by the number of available data within that time frame.

Paired central mixed venous blood and arterial blood gas samples were taken at 10 minutes prior to ergometry starting, and then at $0,10,20$ and 30 minutes, during ergometry and again 10 and 20 minutes after ergometry finished.

Oxygen delivery $\left(\mathrm{DO}_{2}\right)$ was calculated using the equation: $\mathrm{DO}_{2}=\mathrm{CaO}_{2} \times \mathrm{CO}$ where $\mathrm{CaO}_{2}$ (arterial oxygen content $)=\left(1.34 \times \mathrm{Hb} \times \mathrm{SaO}_{2} \times 0.01\right)+\left(0.023 \times \mathrm{PaO}_{2}\right)$. The value 1.34 is known as Hufners constant and 0.023 is the volume of $\mathrm{O}_{2}$ dissolved per $100 \mathrm{ml}$ plasma per $\mathrm{kPa}$.

$\mathrm{CO}_{2}$ production $\left(\mathrm{VCO}_{2}\right)$ was calculated from values of inspired concentrations of $\mathrm{CO}_{2}\left(\mathrm{FiCO}_{2}\right)$ and expired concentrations of $\mathrm{CO}_{2}\left(\mathrm{FeCO}_{2}\right)$ by the E-COVX module via the ventilator using the Bohr equation: $\mathrm{VCO}_{2} \mathrm{kPa}=$ $\mathrm{FiCO}_{2}-\mathrm{FeCO}_{2}$. Oxygen uptake $\left(\mathrm{VO}_{2}\right)$ was calculated by two methods.
1) Method one: The reverse Fick method uses the measure of $\mathrm{CO}$ from the $\mathrm{LiDCO}^{\mathrm{ma}}$ with paired central mixed venous and arterial blood gas samples: $\mathrm{VO}_{2} \mathrm{~mL} / \mathrm{min}=\mathrm{CO} \times\left(\mathrm{CaO}_{2}-\mathrm{CvO}_{2}\right) \times 10$ [15].

2) Method two: Indirect calorimetry calculated $\mathrm{VO}_{2}$ using the E-COVX metabolic module via the ventilator from the value of fraction of inspired $\mathrm{O}_{2}$ $\left(\mathrm{FiO}_{2}\right)$, expiratory minute volume (MV), expired concentrations of $\mathrm{O}_{2}\left(\mathrm{FeO}_{2}\right)$ and $\mathrm{CO}_{2}\left(\mathrm{FeCO}_{2}\right)$ using the equation: $\mathrm{VO}_{2} \mathrm{ml} / \mathrm{min}=\mathrm{MV}\left(\mathrm{FiO}_{2}-\mathrm{FeO}_{2}\right.$ - $\left.\mathrm{FiO}_{2}(\mathrm{FeCO} 2)\right) / 1-\mathrm{FiO}_{2}$. [16]

\section{Statistical analysis}

This is a feasibility study the results of which may be used to power a larger study if appropriate. The study population number was guided by previous work in our unit [17]. All statistical analyses were performed using the SPSS 11 for Mac OS X (version 11.0.2). Demographics were presented for each patient. Continuous data was presented graphically as the mean for the five minutes leading up to each blood gas sampling, unless otherwise stated, except for the first blood sample. For repeated measures an analysis of variance was carried out using the Friedman test to determine any changes occurring in the physiological parameters from baseline to the six different time points. Correlation between the methods was assessed using a Pearson's correlation. The significance difference was set at $\mathrm{p}<0.05$. Percentage changes in physiological parameters are expressed as interquartile range (IQR) and range.

\section{Results}

Feasibility

From the convenience sample of 32 patients were assessed for eligibility, four patients did not meet the inclusion criteria thirteen patients gave assent and twelve patients were studied (Fig. 1). All patients were intubated and ventilated, two by a mandatory mode, nine by assist mode and one on continuous positive airway pressure (CPAP). Mean positive end expiratory pressure (PEEP) was $9 \mathrm{~cm} \mathrm{H}_{2} \mathrm{O}$ with a range of 0 to $12 \mathrm{~cm} \mathrm{H}_{2} \mathrm{O}$ (Table 1).

Ten of the 12 patients completed the 30 minutes ergometry protocol. Insufficient data for analysis was obtained from 2 patients; in one patient this was due to equipment failure and the second patient desaturated during the ergometry session due to heavy secretion load. The ergometry was stopped in order for chest physiotherapy to be delivered. The desaturation was not thought to be related to the ergometry itself. Data was collected for both of these patients up to 
Table 1 Demographic and clinical data of patient's pre ergometry session

\begin{tabular}{|c|c|c|c|c|c|c|c|c|c|c|c|c|}
\hline Patient no. & 0001 & 0002 & 0003 & 0004 & 0005 & 0006 & 0007 & 0008 & 0009 & 0010 & 0011 & 0012 \\
\hline Age - yrs. & $60-69$ & $50-59$ & $60-69$ & $40-49$ & $50-59$ & $\begin{array}{l}30- \\
39\end{array}$ & $\begin{array}{l}70- \\
79\end{array}$ & $30-39$ & $\begin{array}{l}50- \\
59\end{array}$ & $80-89$ & $30-39$ & $20-29$ \\
\hline BMI & 24.9 & 21.4 & 21 & 27 & 27.1 & 22.9 & 24.2 & 47.2 & 17.3 & 32.4 & 23.3 & 27 \\
\hline APACHE II score & 23 & 16 & 19 & 19 & 18 & 7 & 31 & 20 & 18 & 26 & 10 & 13 \\
\hline RASS & -4 & -5 & -3 & +1 & -3 & -4 & -3 & -4 & -4 & -4 & +1 & -4 \\
\hline $\begin{array}{l}\text { Ventilator mode (start of ergometry } \\
\text { session) }\end{array}$ & $\begin{array}{l}\text { Volume } \\
\text { cycled/ } \\
\text { PEEP } 14 \mathrm{~cm} \\
\mathrm{H}_{2} \mathrm{O}\end{array}$ & $\begin{array}{l}\text { Volume cycled/ } \\
\text { PEEP } \\
12 \mathrm{~cm} \\
\mathrm{H}_{2} \mathrm{O}\end{array}$ & $\begin{array}{l}\text { PS/ } \\
\text { PEEP } \\
14 / 10 \mathrm{~cm} \\
\mathrm{H}_{2} \mathrm{O}\end{array}$ & $\begin{array}{l}\text { PS/ } \\
\text { PEEP } \\
10 / 12 \mathrm{~cm} \\
\mathrm{H}_{2} \mathrm{O}\end{array}$ & $\begin{array}{l}\text { CPAP } \\
5 \mathrm{~cm} \\
\mathrm{H}_{2} \mathrm{O}\end{array}$ & $\begin{array}{l}\text { PS/ } \\
\text { PEEP } \\
10 / 5 \\
\mathrm{Cm} \\
\mathrm{H}_{2} \mathrm{O}\end{array}$ & $\begin{array}{l}\text { PS/ } \\
\text { PEEP } \\
14 / 5 \\
\mathrm{~cm} \\
\mathrm{H}_{2} \mathrm{O}\end{array}$ & $\begin{array}{l}\text { PS/ } \\
\text { PEEP } \\
5 / \\
12 \mathrm{~cm} \\
\mathrm{H}_{2} \mathrm{O}\end{array}$ & $\begin{array}{l}\text { PS/ } \\
\text { PEEP } \\
18 / \\
10 \\
\mathrm{~cm} \\
\mathrm{H}_{2} \mathrm{O}\end{array}$ & $\begin{array}{l}\text { PS/ } \\
\text { PEEP } \\
6 / 12 \\
\mathrm{~cm} \\
\mathrm{H}_{2} \mathrm{O}\end{array}$ & $\begin{array}{l}\text { PS/ } \\
\text { PEEP } \\
5 / 14 \\
\mathrm{~cm} \\
\mathrm{H}_{2} \mathrm{O}\end{array}$ & $\begin{array}{l}\text { PS/ } \\
\text { PEEP } \\
16 / 0 \\
\mathrm{~cm} \\
\mathrm{H}_{2} \mathrm{O}\end{array}$ \\
\hline Vasopressor & N/ad & N/ad & N/ad & N/ad & N/ad & N/ad & N/ad & Nil & Nil & Nil & N/ad & Nil \\
\hline SOFA score & 9 & 6 & 8 & 5 & 3 & 5 & 8 & 4 & 4 & 9 & 5 & 3 \\
\hline $\mathrm{FiO}_{2}(\%)$ & 50 & 45 & 50 & 28 & 35 & 28 & 28 & 60 & 40 & 45 & 45 & 40 \\
\hline Diagnosis on admission & AP & $\begin{array}{l}\mathrm{OO} \\
\mathrm{HA}\end{array}$ & $\begin{array}{l}\text { Septic } \\
\text { shock }\end{array}$ & $\begin{array}{l}\text { Septic } \\
\text { shock }\end{array}$ & $\mathrm{OD}$ & $\begin{array}{l}\mathrm{OO} \\
\mathrm{HA}\end{array}$ & AKI & AP & $\mathrm{P}$ & P & $\begin{array}{l}\mathrm{OO} \\
\mathrm{HA}\end{array}$ & $P$ \\
\hline
\end{tabular}

M Male, F Female; BMI Body Mass Index (weight/height ${ }^{2}$ ); RASS Richmond Agitation Sedation Scale; PEEP Positive End Expiratory Pressure, PS Pressure Support; CPAP Continuous Positive Airway Pressure; N/ad Noradrenaline; SOFA Sequential Organ Failure Assessment; FiO ${ }_{2}$ Fraction of Inspired Oxygen; AP Acquired Pneumonia, OOHA Out Of Hospital Arrest, $O D$ Overdose, AKI Acute Kidney Injury, $P$ Pancreatitis.

the point of ergometry cessation. One of the patients who completed the protocol had recurrent muscle contractions during the ergometry session resulting in a 15 second ergometer pause but restarted immediately again and all data was collected and analysed. There are incomplete data sets for $\mathrm{VO}_{2}$ calculations for patient No.2, 7 and 12 due to blood sampling difficulties.

\section{Haemodynamic outcomes}

Median arterial blood pressure, systolic and diastolic blood pressure did not change significantly throughout the exercise protocol $(p=0.89, p=0.66$ and $p=0.63$ respectively). The median resting $\mathrm{HR}$ values did not change throughout the exercise protocol $(p=0.60)$. CO median rest $(n=10)$ value $(6.8 \mathrm{~L} / \mathrm{min}$, IQR $4.4 \mathrm{~L} / \mathrm{min})$ did not change statistically throughout the exercise

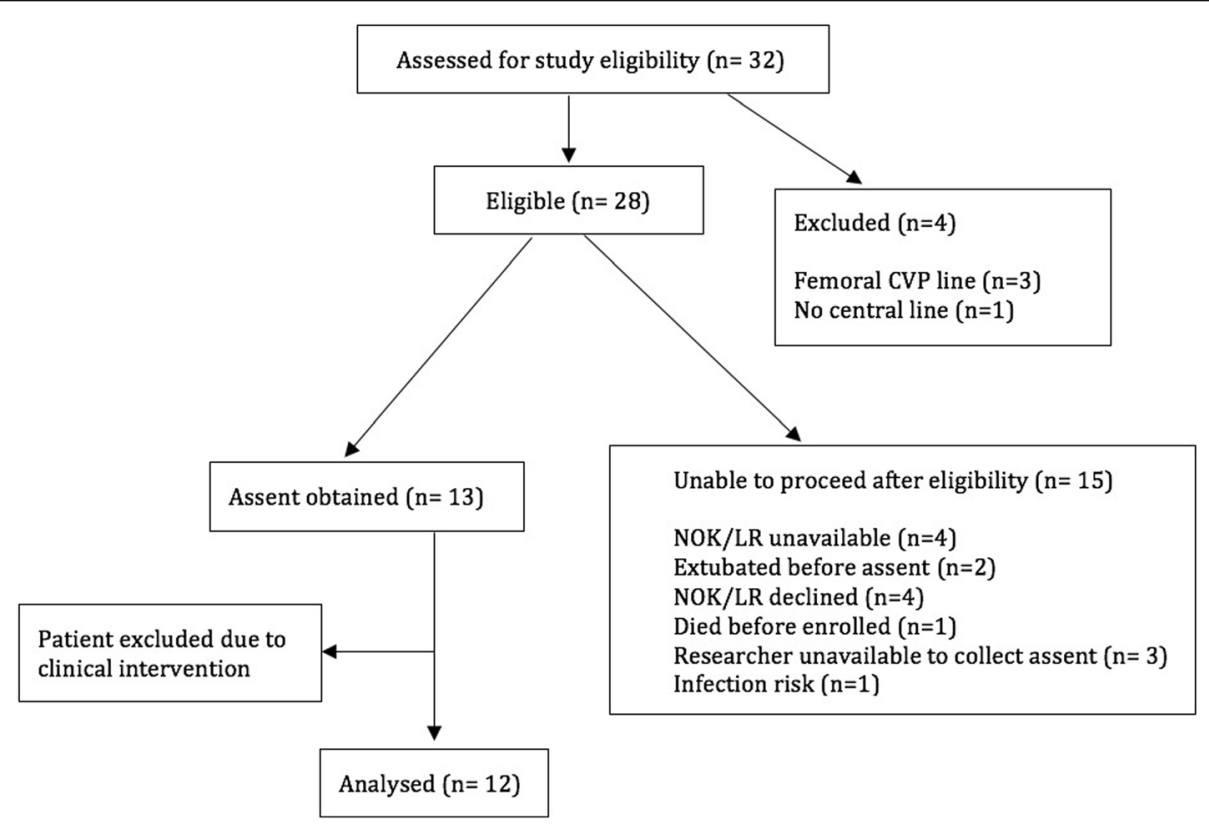

Fig. 1 Flow of participants 
protocol $(p=0.95)$. There were no significant changes in any of the respiratory variables.

\section{Metabolic outcomes}

$\mathrm{DO}_{2}$ median rest value was $943 \mathrm{~mL} / \mathrm{min}$, (IQR $377 \mathrm{~mL} /$ $\min )(n=9)$ and did not change statistically from throughout the exercise protocol $(p=0.98)$ (Fig. 2). Maximum change of $\mathrm{DO}_{2}$ from baseline was $30.5 \%$ for one patient 20 minutes into ergometry session but this reduced to $17.3 \%$ at 20 minutes after recovery.

$\mathrm{ScvO}_{2}(\mathrm{n}=12)$ median rest value was $79.8 \%$, IQR $8.6 \%$ and did not change statistically throughout the exercise protocol $(\mathrm{p}=0.61)$. Maximum change of $\mathrm{ScvO}_{2}$ during the session was a $15.7 \%$ drop during the first ten minutes of ergometry in one patient but this increased to within $1.8 \%$ of its resting levels at the end of the exercise session. $\mathrm{VCO}_{2}(\mathrm{n}=10)$ median rest value was $216.5 \mathrm{~mL} / \mathrm{min}$, IQR $105.5 \mathrm{~mL} /$ min and did not change statistically throughout the exercise protocol $(\mathrm{p}=0.35)$. Maximum change of $\mathrm{VCO}_{2}$ during the session was a decrease of $38.9 \%$ from the median resting value for one patient at the end of the 30-minute exercise session but this increased up to $20.5 \%$ from the baseline 10 minutes later (Fig. 3).

\section{Oxygen uptake $\left(\mathrm{VO}_{2}\right)$}

Median resting $\mathrm{VO}_{2}$ values was $311.5 \mathrm{~mL} / \mathrm{min}$, (IQR $152.5 \mathrm{~mL} / \mathrm{min}$ ) and $160 \mathrm{~mL} / \mathrm{min}$, (IQR $127.2 \mathrm{~mL} /$ min) from the E-COVX $(n=10)$ and the reverse Fick method $(n=8)$ respectively. These did not change statistically throughout the exercise protocol $(p=$ 0.95 and $p=0.84$ ) (Figs. 4 and 5). The maximum change in $\mathrm{VO}_{2}$ from baseline to the end of the 30 minutes exercise was $37.4 \%$ using E-COVX and $59.0 \%$ using reverse Fick method. The biggest change from baseline post the ergometer stopping, measured by E-COVX, was $24.5 \%$ at 20 minutes. The biggest change from baseline post the ergometer stopping, measured by reverse Fick method, was $23.0 \%$ at 10 minutes.

There was poor correlation between the two methods of calculating $\mathrm{VO}_{2}(\mathrm{r}=0.06)$ such that bias assessment was not explored (Fig. 6).

\section{Discussion}

This study reports the feasibility of using the reverse Fick method and indirect calorimetry to monitor metabolic response to upper limb ergometry in critically ill patients. Minimal changes in oxygen uptake support the safety and feasibility of early upper limb ergometry. Additional research is required, to determine the most accurate measure of metabolic response.

Desaturation is the most common reported adverse effect seen during early rehabilitation of patients in ICU [18]. There is concern that desaturations may be related to inadequate cardiorespiratory reserve, limiting the capacity to cope with the increased oxygen demand. [19] Our investigation has not supported this finding. The single desaturation event was attributable to heavy secretion load and resolved by respiratory physiotherapy.

Both direct and indirect methods of $\mathrm{VO}_{2}$ measurement did not significantly change in response to the cycle ergometry. However, in the majority of patients the $\mathrm{VO}_{2}$ measurements using the E-COVX were consistently above those calculated using the reverse Fick method. This warrants further investigation as we cannot account for this discrepancy within the study.

$\mathrm{VO}_{2}$ estimation using the reverse Fick method was precluded on a number of occasions due to technical issues with invasive canulae and lines. $\mathrm{VCO}_{2}$ data from the E-COVX was very stable throughout our study

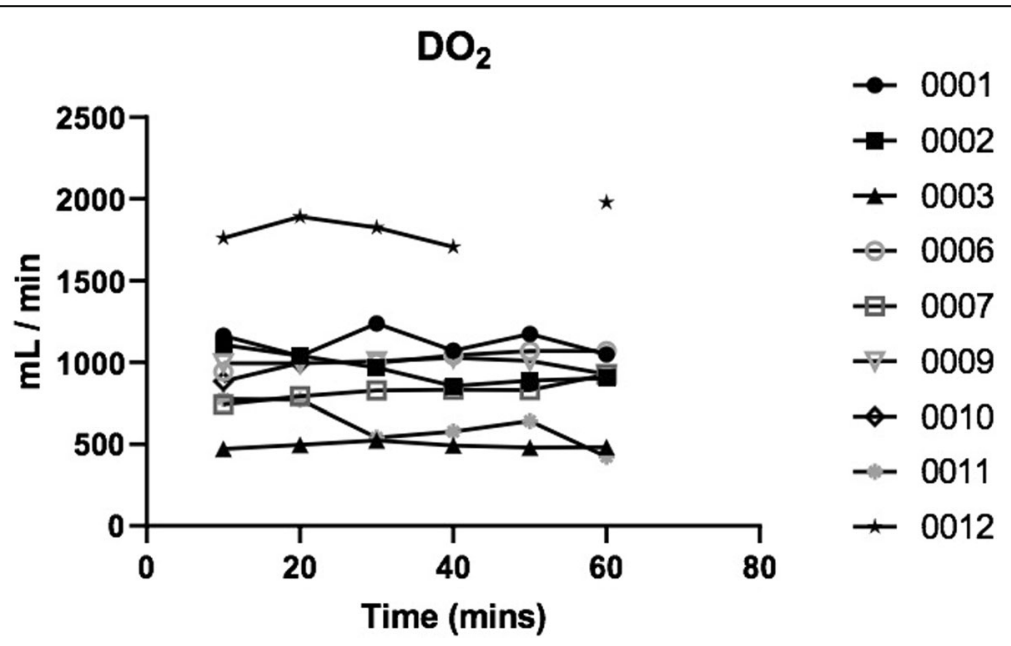

Fig. $2 \mathrm{DO}_{2}$ measurements at six different time points during 60-minute data collection period 


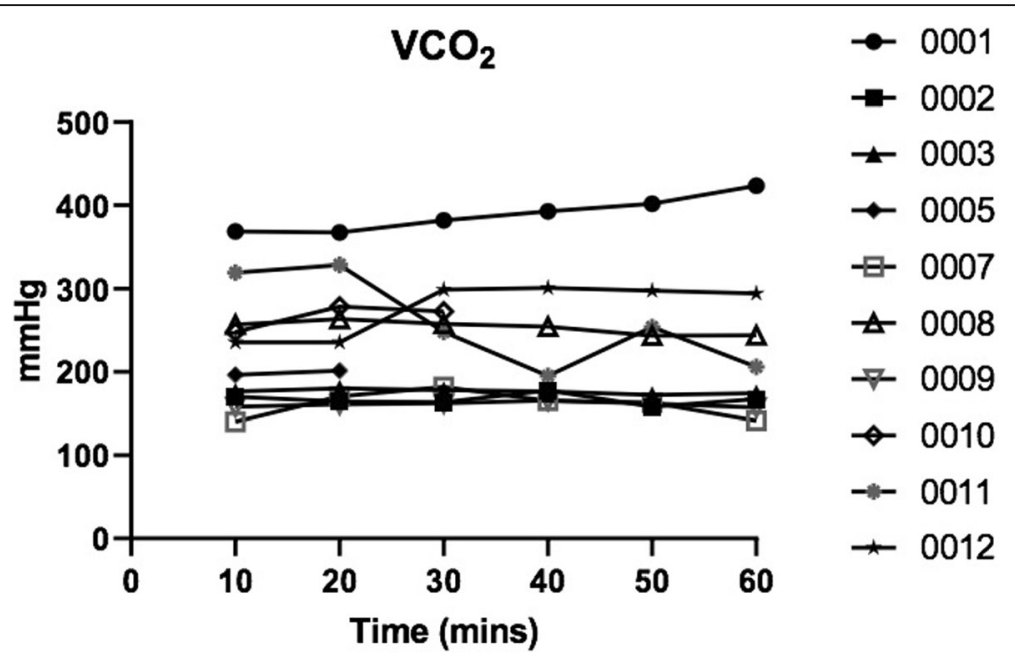

Fig. $3 \mathrm{VCO}_{2}$ measurements at six different time points during 60-minute data collection period

period. However this method relies on the patient at rest being in a steady state, without this it is susceptible to major errors [16].

A number of studies reporting very early commencement of rehabilitation (within 4 days of ICU admission) have demonstrated improved physical outcomes $[8,20$, $21]$ but there remain concerns that critically ill patients are too ill and unstable to undergo these types of interventions [22].

As muscle breakdown and deconditioning can be demonstrated within hours of mechanical ventilation there is increasing interest on rehabilitation and muscle training within the ICU, however the benefits of these interventions remain uncertain. $[3,23]$. It is suggested that mechanical silencing of muscle in the critically ill patients with immobility, sedation, and use of neuromuscular blockade may accentuates muscle breakdown. A number of different methods of passive mechanical loading of muscle in critically ill patients have been used and report reduce wasting, increase muscle strength and being associated with reduced ventilation days and shorter hospital length of stay [23-26]. In bed cycle ergometry is one method of delivering passive muscle loading and on our unit, the early rehabilitation programme has resulted in reduced ventilation days and hospital length of stay [27].

The examination of metabolic costs of the metabolic demands in response to this type of passive mobilization commenced very early during critical illness is not widely studied. A study by Pires-Neto assessing very

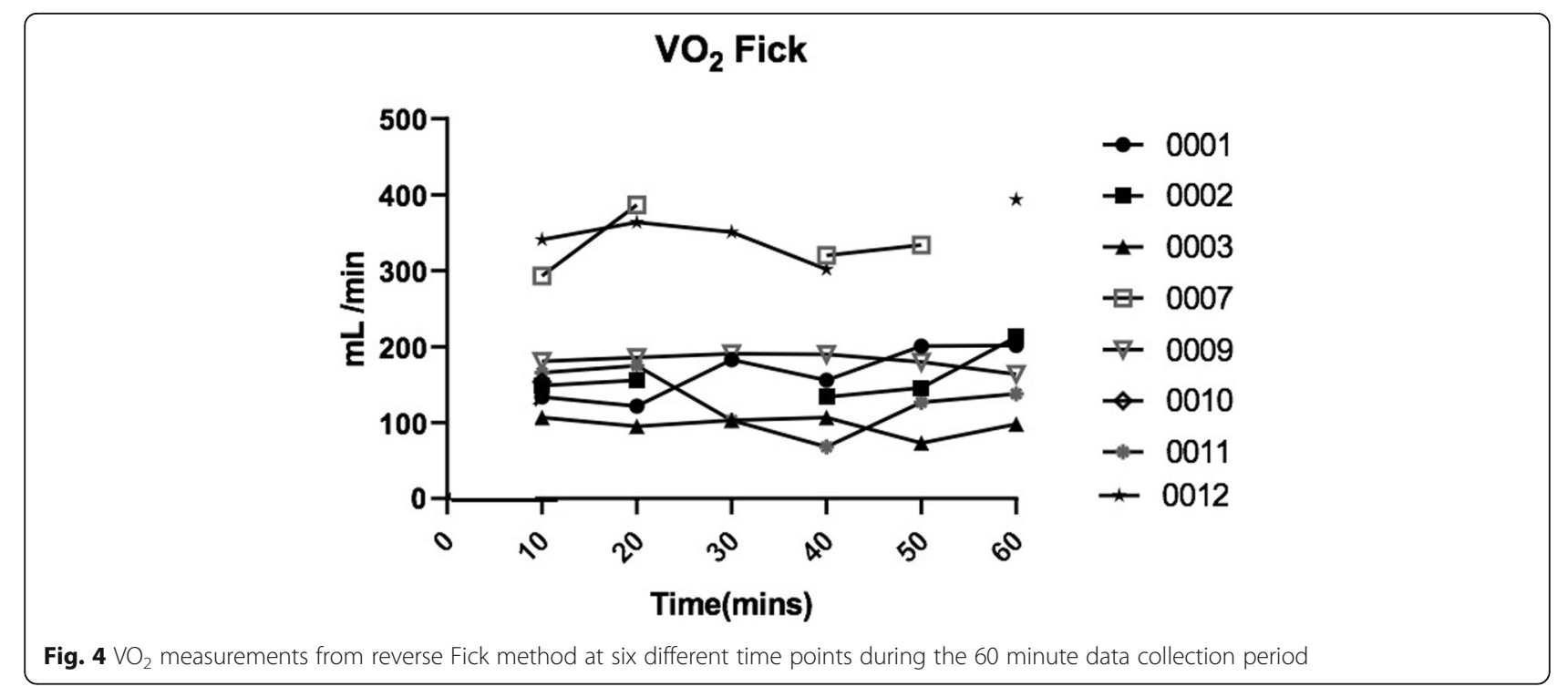




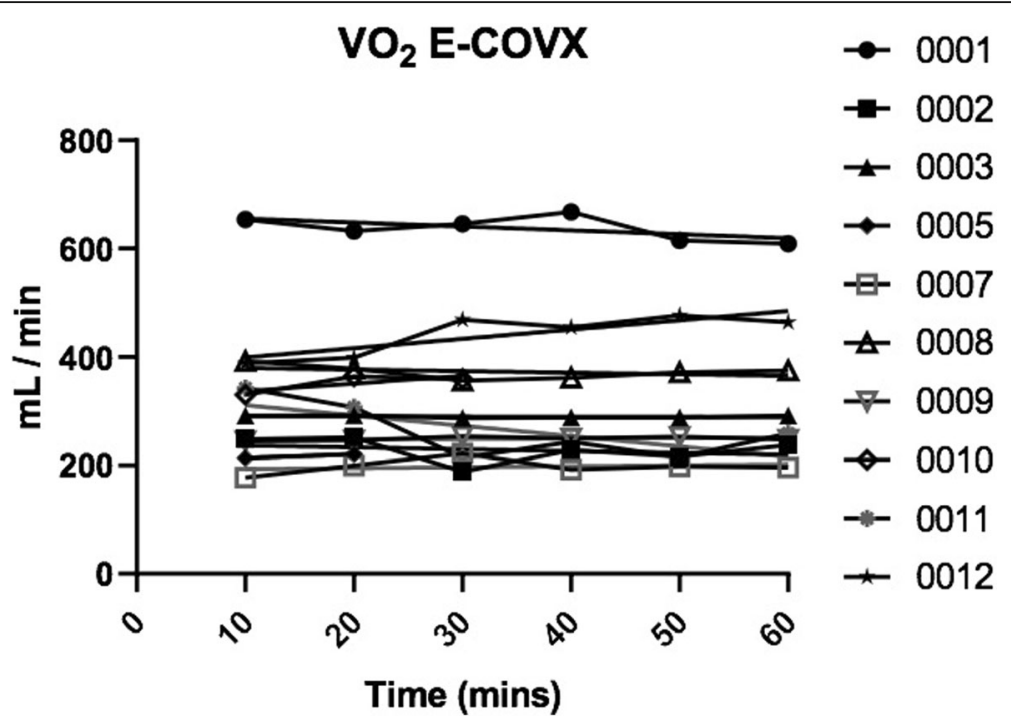

Fig. 5 VO2 measurements from E-COVX at six different time points during 60-minute data collection period

early passive cycle ergometry, albeit in the lower limbs also found no significant changes in cardiorespiratory or metabolic parameters [28]. In this study the Flotrac-Vigileo (Edwards Lifesciences CA USA) was used to assess cardiac output, however the reliability of the Flotrac has been questioned in dynamic situations.[29].

Few studies have examined $\mathrm{VO}_{2}$ in response to other passive interventions although two studies report no significant change in $\mathrm{VO}_{2}$, with either passive chair transfer or physiotherapy treatment $[17,30]$. Our study compared two methods of assessing $\mathrm{VO}_{2}$. Although the $\mathrm{VO}_{2}$ calculations via the E-COVX module in this study produced more variable results than the reverse Fick method, the reproducibility of the reverse Fick method needs to be balanced against the invasiveness of the technique. This difference in results is consistent with previously reported poor correlation and reproducibility between different techniques for $\mathrm{VO}_{2}$ assessment [12]. Further investigation is needed in order to identify optimal techniques of metabolic assessment in ventilated patients.

It is important to acknowledge the limitations of this study. The small number of participants $(n=12)$ and the

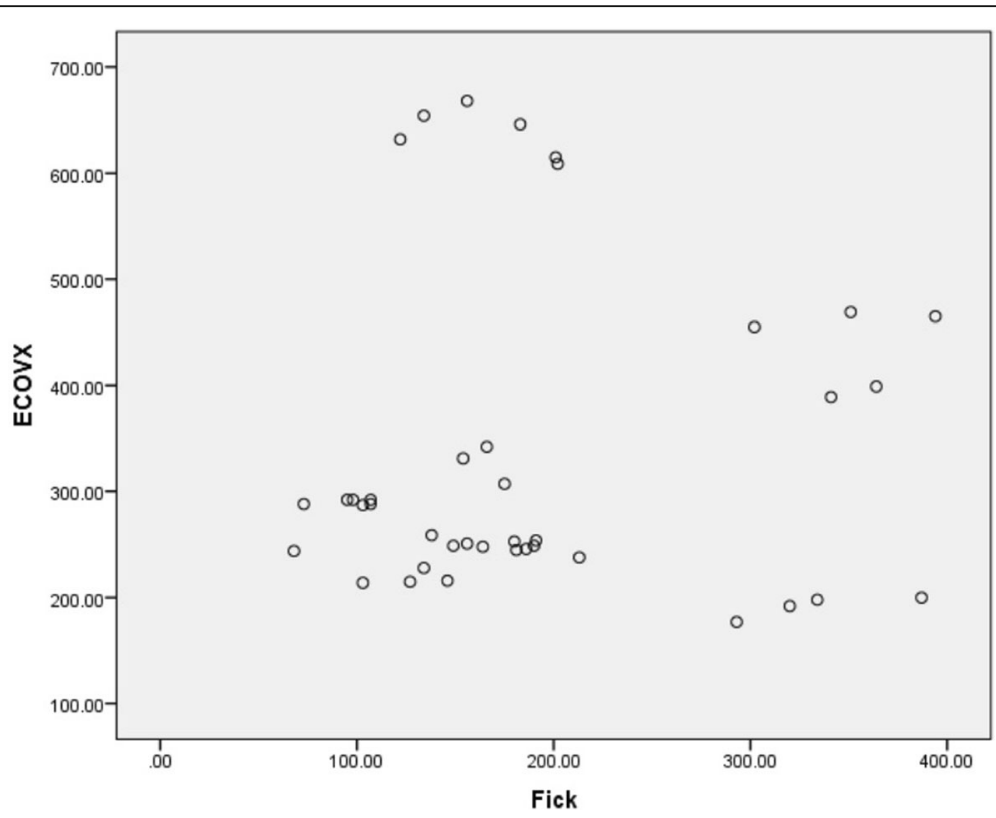

Fig. 6 Comparison of both methods of calculating $\mathrm{VO}_{2}$ (E-COVX and Fick) 
heterogeneity of these patients with regards to age and diagnosis means extrapolation of these results to all ICU patients is not justified. Technical issues resulted in incomplete data sets. Although the majority of the patients were deeply sedated two patients had a RASS score above -2 , The data from the motomed machine did not indicate if there was any active participation from the patient during the protocol. Although a possibility, such active participation would be expected to result in increases in oxygen uptake which was not seen.

\section{Conclusions}

Measuring the metabolic demands of upper limb cycle ergometry in critically ill patients appears to be feasible and results in minimal increase in metabolic demands. Our study supports the notion that perceived benefit of early physical rehabilitation may outweigh concerns of adding to the physiological demands during the acute stages of illness. Further research is needed to determine how monitoring patient workload during rehabilitation could be used to personalise rehabilitation strategies during the course of their illness.

\section{Abbreviations}

AKI: Acute kidney injury; BMI: Body mass index; BP: Blood pressure; $\mathrm{CaO}_{2}$ : Arterial oxygen content; $\mathrm{CO}$ : Cardiac output; $\mathrm{CO}_{2}$ : Carbon dioxide; CPAP: Continuous positive airway pressure; $\mathrm{CVO}_{2}$ : Venous oxygen content; CVP: Central venous pressure; $\mathrm{DO}_{2}$ : Oxygen delivery; ECG: Electrocardiogram; EMP: Early mobility programme; $\mathrm{FeO}_{2}$ : Expired oxygen; $\mathrm{FeCO}_{2}$ : Expired carbon dioxide; $\mathrm{FiO}_{2}$ : Inspired oxygen; $\mathrm{FiCO}_{2}$ : Inspired carbon dioxide; $\mathrm{F} /$ M: Female/ male; HR: Heart rate; Hb: Haemoglobin; ICU: Intensive care unit; IQR: Inter quartile ratio; LiDCO: Lithium dilution cardiac output; MV: Minute ventilation; N/ad: Noradrenaline; NOK/LR: Next of kin/living relative; O2: Oxygen; OD: Overdose; OOHA: Out of hospital arrest; $\mathrm{PaO}_{2}$ : Partial pressure of oxygen; PEEP: Positive end expiratory peep; PiCCO: Pulse contour cardiac output; PS: Pressure support; RASS: Richmond agitation sedation score; REC: Research ethics committee; RR: Respiratory rate; $\mathrm{SaO}_{2}$ : Blood oxygen saturation; $\mathrm{SCvO}_{2}$ : Central venous oxygen saturation; SV: Stroke volume; $\mathrm{VCO}_{2}$ : Carbon dioxide production; $\mathrm{VO}_{2}$ : Oxygen uptake; VT: Tidal volume
}

\section{Acknowledgements}

Not applicable.

\section{Authors' contributions}

OW and RC were involved in this study conception and design. OW was involved in the data acquisition and analysis. OW drafted the manuscript. $O W$ and $R C$ were involved in the data interpretation and $R C$ and $A B$ assisted in critically revising the draft manuscript. $O W A B$ and $R C$ read and approved the final manuscript.

\section{Funding}

Andrew Bates is funded by a National Institute for Health Research (NIHR), (Pre-doctoral clinical academic fellowship) for this research project. This article presents independent research funded by the National Institute for Health Research (NIHR). The views expressed are those of the author and not necessarily those of the NHS, the NIHR or the Department of Health and Social Care.

\section{Availability of data and materials}

The datasets generated during the current study are available from the corresponding author on reasonable request.

\section{Ethics approval and consent to participate}

Ethical approval for the study was given by the South-Central Hampshire Research ethics Committee (REC 14/SC/1398). Written informed assent was obtained from the patient's next of kin/ legal representative (NOK/LR) prior to enrolling study patients. Consent was obtained from the patient once they regained capacity.

\section{Competing interests}

The authors certify that there is no competing interest with any financial organisation regarding the material discussed in the manuscript.

\section{Consent for publication}

Not applicable.

\section{Author details}

${ }^{1}$ Centre for Innovation and Leadership, Faculty of Health Sciences, University of Southampton, Building 45, Room 2035, Highfield Campus, S017 1BJ

Southampton, UK. ${ }^{2}$ Critical Care Anaesthesia and Perioperative Research Unit and Integrative Physiology, Clinical Experimental Sciences and NIHR Respiratory Biomedical Research Unit, University Hospital Southampton NHS Foundation Trust and University Hospital Southampton, Southampton, UK.

Received: 15 May 2020 Accepted: 25 December 2020

Published online: 25 January 2021

\section{References}

1. Hospital Admitted Patient Care Activity 2018-19. 2019; National stastics]. Available from: https://digital.nhs.uk/data-and-information/publications/ statistical/hospital-admitted-patient-care-activity/2018-19.

2. Needham DM. Mobilizing patients in the intensive care unit - Improving neuromuscular weakness and physical function. Jama-Journal of the American Medical Association. 2008;300(14):1685-90.

3. Puthucheary ZA, et al. Acute Skeletal Muscle Wasting in Critical IIIness. Jama-Journal of the American Medical Association. 2013;310(15):1591-600.

4. Truong AD, et al. Bench-to-bedside review: Mobilizing patients in the intensive care unit - from pathophysiology to clinical trials. Critical Care. 2009;13:4

5. Griffiths J, et al. An exploration of social and economic outcome and associated health-related quality of life after critical illness in general intensive care unit survivors: a 12-month follow-up study. Critical Care. 2013; 17:3.

6. Herridge MS, et al. Functional Disability 5 Years after Acute Respiratory Distress Syndrome. N Engl J Med. 2011;364(14):1293-304.

7. Morris $\mathrm{PE}$, et al. Early intensive care unit mobility therapy in the treatment of acute respiratory failure. Crit Care Med. 2008;36(8):2238-43.

8. Schweickert WD, et al. Early physical and occupational therapy in mechanically ventilated, critically ill patients: a randomised controlled trial. Lancet. 2009;373(9678):1874-82.

9. Burtin C, et al. Early exercise in critically ill patients enhances short-term functional recovery. Crit Care Med. 2009;37(9):2499-505.

10. Chiang $\mathrm{LL}$, et al. Effects of physical training on functional status in patients with prolonged mechanical ventilation. Phys Ther. 2006;86(9):1271-81.

11. Rehal MS, et al. Measuring energy expenditure in the intensive care unit: a comparison of indirect calorimetry by E-sCOVX and Quark RMR with Deltatrac II in mechanically ventilated critically ill patients. Critical care (London, England). 2016;20:54

12. Black C, Grocott MPW, Singer M. Metabolic monitoring in the intensive care unit: a comparison of the Medgraphics Ultima, Deltatrac II, and Douglas bag collection methods. Br J Anaesth. 2015;114(2):261-8.

13. von Elm E, et al. The Strengthening the Reporting of Observational Studies in Epidemiology (STROBE) statement: guidelines for reporting observational studies. Lancet. 2007;370(9596):1453-7.

14. Hodgson $\mathrm{CL}$, et al. Expert consensus and recommendations on safety criteria for active mobilization of mechanically ventilated critically ill adults. Critical Care. 2014;18:6.

15. Schneeweiss $B$, et al. Assessment of oxygen-consumption by use of reverse Fick-principle and indirect calorimetry in critically ill patients. Clin Nutr. 1989; 8(2):89-93.

16. Takala J. Application Guide Gas Exchange and indirect calorimetry. 2013. 1-24.

17. Collings N, Cusack R. A repeated measures, randomised cross-over trial, comparing the acute exercise response between passive and active sitting in critically ill patients. Bmc Anesthesiology, 2015. 15. 
18. Adler J, Malone D. Early mobilization in the intensive care unit: a systematic review. Cardiopulmonary physical therapy journal. 2012;23(1):5-13.

19. Stiller K, Phillips A, Lambert P. The safety of mobilisation and its effect on haemodynamic and respiratory status of intensive care patients. Physiotherapy Theory Practice. 2004;20(3):175-85.

20. Morris PE, et al. Standardized Rehabilitation and Hospital Length of Stay Among Patients With Acute Respiratory Failure A Randomized Clinical Trial. Jama-Journal of the American Medical Association. 2016;315(24):2694-702.

21. Routsi C, et al. Electrical muscle stimulation prevents critical illness polyneuromyopathy: a randomized parallel intervention trial. Critical Care. 2010;14:2.

22. Jolley SE, et al. Point Prevalence Study of Mobilization Practices for Acute Respiratory Failure Patients in the United States. Crit Care Med. 2017;45(2): 205-15.

23. Gayan-Ramirez G, Decramer M. Effects of mechanical ventilation on diaphragm function and biology. Eur Respir J. 2002;20(6):1579.

24. Griffiths RD. Effect of passive stretching on the wasting of muscle in the critically ill: Background. Nutrition. 1997;13(1):71-3.

25. Llano-Diez M, et al. Mechanisms underlying ICU muscle wasting and effects of passive mechanical loading. Critical Care. 2012;16:5.

26. Machado ADS, et al. Effects that passive cycling exercise have on muscle strength, duration of mechanical ventilation, and length of hospital stay in critically ill patients: a randomized clinical trial. J Bras Pneumol. 2017;43(2): $134-9$.

27. van Willigen Z, et al., Quality improvement: The delivery of true early mobilisation in an intensive care unit. BMJ quality improvement reports, 2016. 5(1): p. u211734.w4726

28. Pires-Neto C. R., et al., Very early passive cycling exercise in mechanically ventilated critically ill patients: physiological and safety aspects-a case series. PLoS One. 2013;8(9):e74182.

29. Maeda. T, Hamaguchi E, et al. The accuracy and trending ability of cardiac index measured bythe fourth-generationFlotracVigileo system and the Fickmethod in cardica surgery patients. J Clin Monit Comput. 2019;33:76776.

30. Berney $S$, Denehy $L$. The effect of physiotherapy treatment on oxygen consumption and haemodynamics in patients who are critically ill. Australian Journal of Physiotherapy. 2003:49(2):99-105.

\section{Publisher's Note}

Springer Nature remains neutral with regard to jurisdictional claims in published maps and institutional affiliations.

Ready to submit your research? Choose BMC and benefit from:

- fast, convenient online submission

- thorough peer review by experienced researchers in your field

- rapid publication on acceptance

- support for research data, including large and complex data types

- gold Open Access which fosters wider collaboration and increased citations

- maximum visibility for your research: over $100 \mathrm{M}$ website views per year

At $\mathrm{BMC}$, research is always in progress.

Learn more biomedcentral.com/submissions 